\title{
AUTOPSIAS DE LO REAL: RESUCITANDO A LOS MUERTOS
}

\author{
Noël Valis
}

Yale University

\section{RESUMEN}

El sentido de lo real, de lo material - el cuerpo sin vida - como una inextricable parte de lo sagrado, no desaparece del ambiente secular de los siglos XIX y XX. En los relatos analizados en este artículo se estudia cómo en determinadas narrativas humanitarias centradas en la práctica de la autopsia y la momificación, las huellas del catolicismo actúan como una suerte de discurso espectral de la imaginación, en que lo real se configura en formas de lo siniestro, lo monstruoso o lo sagrado.

PALABRAS CLAVE: Autopsia. Momificación. Catolicismo. Pi y Molist. González Velasco.

\section{AUTOPSIES OF THE REAL: RESURRECTING THE DEAD}

\section{ABSTRACT}

The sense of the real, or the material — the dead body - as an inextricable part of the sacred does not disappear in the secular environment of the nineteenth and twentieth centuries. This article analyzes specific humanitarian narratives centered on the practice of autopsy and mummification, in which the traces of Catholicism act as a kind of spectral discourse of the imagination, where the real is configured in forms of the uncanny, the monstrous or the sacred.

KEY WORDS: Autopsy. Mummification. Catholicism. Pi y Molist. González Velasco.

La práctica de la autopsia nos sugiere que un cadáver no es simplemente un cuerpo sin vida. Entre los diversos sentimientos que puede producir la contemplación del cuerpo muerto se encuentra incluso «un sentido de reverencia que las fotografías y los modelos no consiguen provocar» al ejercer este arte ahora en desuso, según médicos como Frank González-Crussi y otros. Un estudiante de medicina llega a hablar de la clase de anatomía como «una poderosa experiencia sagrada» ${ }^{1}$. Los cadáveres de los que hablaré en los

1 Cit. en Zuger, A. (2004), Anatomy Lessons, a Vanishing Rite for Young Doctors, The New York Times, 23 de marzo. 
siguientes relatos son considerados como algo poderosamente sagrado por parte de aquellos que los amaron, los temieron e incluso los diseccionaron o embalsamaron. Todos los individuos masculinos de estas historias son doctores o gente asociada a la medicina; todos ellos, por razones varias y dentro de contextos culturales distintos, se sintieron llamados a «resucitar» un cadáver, ya fuera literal, ya simbólicamente, bien a través de la autopsia o de su contrario, la momificación; y todos ellos conmemoran a los muertos dentro de la cultura católica hispánica o de sus huellas. Casi todos los cadáveres de las historias (menos el de un niño) son femeninos y, en su mayoría, murieron tras contraer una enfermedad. Dichas historias varían entre sí en la época y el contexto cultural en que se desarrollan; sin embargo, mi punto de partida (y énfasis) para el estudio de todas ellas es la medicina de la España del siglo XIX, entendida doblemente, por un lado, como un modo de observar la manera en que el catolicismo habita presumiblemente en las formas seculares o científicas de ver y experimentar el cuerpo; y, por otro, como un marco para entender la manera en que un cuerpo sin vida puede ser al mismo tiempo real e imaginario, vivo y ausente ${ }^{2}$.

El sentido de lo real o lo profano, de lo material - el cuerpo sin vidacomo una inextricable parte de lo sagrado o lo divino no desaparece del ambiente secular de los siglos XIX y XX, en contra de la opinión predominante que ha consagrado el ascenso del hombre técnico. Según esta visión, el «ver por uno mismo» (el sentido literal de «autopsia») se transforma en la mirada clínica del siglo XVIII que, como propugnaba Foucault, constituía tanto una forma de conocimiento como una forma de control del conocimiento ${ }^{3}$. Sin

2 Nota del traductor: Debido a su importancia clave en este trabajo, téngase en cuenta la dificultad en la traducción del verbo inglés to haunt (y, junto a este, el sustantivo haunting y los adjetivos haunting y haunted), que podemos traducir aquí por medio de una perífrasis: 'habitar algo en el interior de una cosa o persona de manera persistente u obsesiva a modo de fantasma o espectro'. Dada la complejidad de dicho término y la imposibilidad de encontrar una traducción fija, se emplea en este caso el verbo 'habitar', aunque en posteriores ocasiones aparece traducido por medio de otro tipo de construcciones (como «obsesión», «espectral»o «posesión») más adecuadas según el contexto.

3 Véase Foucault, M. (1975), The Birth of the Clinic. An Archaeology of Medical Perception, Nueva York, Vintage, pp. xiii-xiv, 121, 137; también STAFFORD, B. (1991), Body Criticism. Imaging the Unseen in Enlightenment Art and Medicine, Cambridge, MIT Press, p. 47. MandRESSI, R. (2003), Le regard de l'anatomiste. Dissections et invention du corps en Occident, París, Editions du Seuil, p. 12, se refiere a una «cultura de la anatomía», o sea, «una vasta red de prácticas, de discursos y de conocimientos» enfocada en el cuerpo humano. $[N$. del $t$ : de aquí en adelante, las traducciones al español de las citas de todas aquellas obras que en la bibliografía se mencionan en un idioma distinto al castellano son nuestras.] 
embargo, esta misma mirada es también parte de lo que Thomas Laqueur llama una «narrativa humanitaria». Laqueur estudia «cómo los detalles sobre el sufrimiento de los cuerpos de los demás generan un sentimiento de compasión y cómo esa compasión viene a entenderse como un imperativo moral para emprender una acción de mejora». Cita además Laqueur una particular «confianza en el detalle como signo de verdad» en estas narrativas, que incluyen géneros tales como «la novela realista, la autopsia, el informe clínico y la investigación social», todos ellos «hijos de la revolución empirista del siglo XVII ${ }^{4}$.

En estas relaciones, el cuerpo se convierte en el foco y el lugar de la investigación: cuerpos sin vida, cuerpos enfermos, cuerpos pobres, cuerpos en conflicto. Este hilo narrativo, para el cual Laqueur halla ejemplos en su mayoría, aunque no exclusivamente, en la Gran Bretaña de los siglos XVIII y XIX, también existe en España y otros lugares. Yo sugeriría, no obstante, que la narrativa humanitaria española, a la cual pertenece la medicina moderna, deriva solo parcialmente del lado empirista de la realidad y que una imaginación católica como medio de ver y actuar debe ser tomada también en consideración como parte de este impulso humanitario español.

En mi argumentación el catolicismo a menudo actúa como una suerte de discurso espectral de la imaginación en estas narrativas humanitarias. Y esta cualidad espectral es doble. En primer lugar, el catolicismo da forma al entendimiento narrativo de «lo real», el cual, a su vez, produce un efecto de desdoblamiento que se configura como lo siniestro o lo monstruoso o lo sagrado. En segundo lugar, el catolicismo, atacado en una época de creciente secularización, a menudo sugiere un lenguaje de secreta pérdida — la suya propia - a través de figuras de ausencia, que paradójicamente abren la vía para legitimar y producir otras formas de autoridad, como la profesionalización de la medicina moderna. Estas narrativas humanitarias se construyen imaginativamente sobre la fundación de los restos del catolicismo. El catolicismo como fuente de autoridad, de conocimiento y de percepción en la España del siglo XIX produce «fantasmas»: el fantasma de lo que fue real y el fantasma de sí mismo. Las narrativas humanitarias que destaco en el presente trabajo se basan en confesiones espectrales, en la obsesión que produce aquello que no se dijo, aquello que se perdiós. Es también importante señalar que,

4 Laqueur, T. (1989), Bodies, Details, and the Humanitarian Narrative. En HunT, L. (coord.), The New Cultural History, Berkeley, University of California Press, pp. 176-177.

5 En un nivel personal y existencial, CHACEL, R. (1980), La confesión, Barcelona, Edhasa, p. 96, explora la confesión como un «análisis espectral de la voluntad». ZAMBRANO, M. (1988), La confesión. Género literario, Madrid, Mondadori, p. 65, ve la confesión como la 
al mismo tiempo, se produce otro fenómeno: de esta intensa, personal y aterradora relación con lo que alguna vez fue real o estuvo vivo, y que produce dobles en las formas de lo siniestro, lo monstruoso y lo sagrado, surgen narrativas de la imaginación que buscan alcanzar sus fines hasta el punto de incurrir en la transgresión. Las narrativas del siglo XX con las cuales concluyo - un caso de necrofilia en Key West (Florida) en los años treinta, el cuerpo de Eva Perón y la autopsia de una víctima de sida - engendran asimismo, a veces por motivos dudosamente humanitarios, dobles similares de un cuerpo sin vida en un esfuerzo por agarrarse a aquello que va más allá de nuestro entendimiento.

Efectivamente, el catolicismo porta consigo la semilla de la transgresión al estar basado en nociones de lo sagrado y lo profano, en lo escatológico como $\sigma \chi \alpha \tau o \varsigma$ (lo relativo a la vida de ultratumba) y como $\sigma \kappa \alpha \tau o ́ \varsigma$ (lo excrementicio), conceptos estos que no quedan separados a pesar de estar explícitamente enunciados en un paradigma de contrarios. Estas ideas en relación, destinadas a establecer categorías y fronteras, persisten en el siglo XIX dentro de un discurso católico cada vez más militante (y a menudo defensivo), e igualmente en narrativas como formas de lo normal y lo patológico. Tales discursos y narrativas son también signos de un frágil orden social que se constituyó de un modo demasiado estricto para soportar múltiples presiones de cambio y, en particular, la inexorable ola de la secularización. El catolicismo decimonónico, en su lucha e interacción con interpretaciones no religiosas del mundo, produce, paradójicamente, formas secularizadas de transgresión, formas de desdoblamiento en las que los límites de las cosas, las identidades y las normas se desdibujan, principalmente la frontera entre la vida y la muerte, entre lo sagrado y lo no sagrado.

De este modo, empleo la autopsia y la momificación como figuras de ausencia que producen un efecto espectral, de posesión, procedente de la propia actividad de la imaginación. Los cuerpos que aparecen en estos textos están muertos e, igualmente, vivos. Como fetiches, se trata de los difuntos conmemorados, quienes al mismo tiempo están suspendidos en el aura de la vida. En este aspecto, funcionan lógicamente como reliquias, dada la cultura católica en que están inmersas. En un sentido más amplio, el efecto de esta posesión espectral puede verse como el generador de una forma específica de lo que Paul Valéry denominó nuestro Cuarto Cuerpo, el cual, decía, puede fácilmen-

\footnotetext{
necesidad imperiosa de soltar las frustradas criaturas embrionarias que habitan dentro del ser: «conatos de ser... Larvas, conatos, seres muertos en su crecimiento». En otras palabras, estamos acosados por espectros creados por nosotros mismos.
} 
te ser llamado tanto «Cuerpo Real» como «Cuerpo Imaginario» 6 . Más allá del cuerpo que conocemos, del que otros conocen y del cuerpo interior, existe un cuarto cuerpo, el cual, si tan siquiera lográramos comprender, respondería todas las preguntas trascendentales sobre la vida y la muerte. Por ello es real e imaginario.

El Cuarto Cuerpo recuerda a algo que Maurice Blanchot dijo en una ocasión atendiendo a la correspondencia entre la imagen y los restos mortales: «La imagen, a primera vista, no se parece al cadáver, pero sería posible que la extrañeza cadavérica correspondiese también a la imagen. Lo que se llama despojo mortal escapa de las categorías comunes: hay frente a nosotros algo que ni es el viviente en persona, ni una realidad cualquiera, ni el que estaba vivo, ni otro, ni ninguna otra cosa». Continúa Blanchot diciendo que «la semejanza cadavérica es una obsesión, [...] lo que obsesiona es lo inaccesible de lo que no podemos deshacernos, lo que no encontramos y por eso no podemos evitar. Lo inasible es aquello de lo que no se escapa» ${ }^{7}$. En este sentido, el Cuarto Cuerpo de Valéry ha adquirido un doble espectral, el cuerpo sin vida, que continúa siendo al mismo tiempo imaginario y real, y sugiere una forma de lo real que es tan absolutamente real que no podemos comprenderla ni eludirla. El catolicismo espectral al cual me refiero posee este mismo tipo de realidad, basada en lo «realmente real» de la creencia religiosa de la cual hablan, entre otros, Geertz, pero produciendo ahora su propio desdoblamiento en extrañas formas de lo siniestro, lo monstruoso y lo sagrado ${ }^{8}$.

Thomas Laqueur, se señalaba antes, considera el uso de detalles como algo significativo a la hora de producir tales narrativas humanitarias. El detalle, dice, es un «signo de verdad». El detalle, sugeriría yo, produce una forma (o formas) de verdad que descansa sobre complejas interpretaciones de lo real. De modo significativo, en los textos del siglo XIX examinados aquí, estos detalles - entendidos como una incitación al compromiso empático con el cuerpo doliente de los otros - son cuestionados a menudo de manera simultánea como parte de una formación o práctica discursiva que aún no ha sido institucionalizada o legitimada completamente. Como resultado, la motivación humanitaria de estas narrativas sirve también a menudo para autorizar

6 VAlery, P. (1945), Réflexions simples sur le corps. En Variété V, 38. ${ }^{a}$ ed., París, Gallimard, p. 74.

7 Blanchot, M. (2002), Las dos versiones de lo imaginario. En El espacio literario, trad. Vicky Palant y Jorge Jinkis, Madrid, Editora Nacional, pp. 227, 230.

8 GeERTZ, C. (1973), Religion as a Cultural System. En The Interpretation of Cultures. Selected Essays, Nueva York, Basic Books, p. 112. 
otra narrativa o modo de ver y hacer las cosas, prácticas moldeadas por la creencia religiosa que, por tanto, ponen en duda precisamente qué «signo[s] de verdad»s se producen aquí.

Mi primera narrativa humanitaria del siglo XIX procede de un texto titulado Examen médico del siguiente pasage de Chateaubriand en sus «Mémoires d'outre-tombe»: "Lejos de mi cadáver la sacrílega autopsia...": o sea Consideraciones sobre el impulso y carácter comunicados por la anatomía a la medicina moderna (1852). Con esta memoria, su autor, Emilio Pi y Molist se presentaba a sí mismo como candidato a ingresar en la Academia de Medicina y Cirugía de Barcelona. Pi y Molist (1824/1826-1892) es representante de una raza de doctores que no solo tenían concepciones progresistas y reformistas, sobre todo en cuestiones del derecho médico y la psiquiatría, sino que también estaban profundamente interesados en asuntos literarios y estéticos. Autor de Primores del Don Quijote en el concepto médico-psicológico (1886) $\mathrm{y}$, según algunos le atribuyen, de la novela Misterios del hospital (1883), Pi y Molist hizo aportaciones significativas a la literatura sobre enfermedades mentales y colaboró con la construcción de instalaciones adecuadas para los enfermos mentales, orquestando durante más de veinticinco años una incesante campaña para edificar un nuevo instituto psiquiátrico en el Hospital de la Santa Cruz de Barcelona9 ${ }^{9}$.

En su Examen médico, Pi y Molist toma como punto de partida una cita de las Mémoires d'outre-tombe (1849-50) del escritor católico Chateaubriand para defender la legitimidad de la autopsia médica. Si bien la disección no estaba prohibida en España durante este periodo, existía una resistencia notable a esta práctica procedente no solo de representantes de la Iglesia y de la

9 Entre las publicaciones de Pi y Molist pueden destacarse Estadística de los Departamentos de Locos del Hospital de Santa Cruz de Barcelona, correspondiente al segundo semestre de 1855 (1856); Proyecto médico razonado para la construcción del Manicomio de Santa Cruz de Barcelona (1860); Colonia de orates de Gheel (Bélgica) (1856); ¿Qué relaciones guardan las enfermedades mentales con las formas del cráneo? (1870), etc. Para más información sobre Pi y Molist, véase FUSTER POMAR, J. (1971), El Instituto Mental de Santa Cruz. En El Hospital de Santa Cruz y de San Pablo. El Hospital de Barcelona, Presentación de J. Capmany Casamitjana, Barcelona, Gustavo Gili, pp. 205-213; Sancho DE SAn RoMÁN, R. (1959), La obra psiquiátrica del doctor Pi y Molist, Seminario de Historia de la Medicina (Salamanca), 2 (5), pp. 229-247; ElíAs DE Molins, A. (1972), Diccionario biográfico y bibliográfico de escritores y artistas catalanes del siglo XIX, 2 vols., Hildesheim y Nueva York, Georg Olms Verlag (orig. 1889, 1895); y VALIS, N. (2005), Reading the NineteenthCentury Spanish Novel. Selected Essays, Newark, Juan de la Cuesta, pp. 257-272. 
población en general, sino también de un buen número de doctores ${ }^{10}$. El conflicto entre las autoridades seculares y religiosas era especialmente visible en la disputa en torno al uso médico de cadáveres en los hospitales. Pi y Molist, que era católico devoto, propugnó con firmeza la autopsia como una herramienta de conocimiento médico para identificar la patología de las enfermedades. Además, usó esta oportunidad como pretexto para abordar la cuestión, más general, de la legitimidad de la ciencia misma, diciendo: "Quieta y casi abandonada en nuestra patria la prensa científica, diríase que la literaria se arroga el derecho de juzgar en todas las materias, y dirigir exclusivamente el rumbo de la opinión pública $\rangle^{11}$. Para este fin, reúne tres tipos distintos de discurso e instituciones que respalden su argumentación: la profesión médica misma, simbolizada en la Academia de Medicina y Cirugía de Barcelona y en la figura histórica del doctor Francisco Salvá y Campillo; textos religiosos, más concretamente los de Jaime Balmes y fray Luis de Granada; y, finalmente, el ejemplo literario del propio Chateaubriand.

En primer lugar, tenemos a continuación la cita de Chateaubriand, escritor muy admirado y traducido en España ${ }^{12}$ :

Qu'on sauve mes restes d'une sacrilège autopsie; qu'on s'épargne le soin de chercher dans mon cerveau glacé et dans mon cœur éteint le mystère de mon être. La mort ne révèle point les secrets de la vie ${ }^{13}$.

\section{Y la traducción de Pi y Molist:}

Lejos de mi cadáver la sacrílega autopsia; en balde fuera buscar en mi helado celebro y en mi yerto corazón el misterio de mi ser; que no descubre la muerte los arcanos de la vida ${ }^{14}$.

Pi y Molist inserta a continuación una cita de Balmes:

10 ArÉChaga Martínez, J. (1977), La anatomía española en la primera mitad del siglo $X I X$, Granada, Universidad de Granada, pp. 67-68; y VALIS (2005), pp. 267-268.

11 Pi y Molist, E. (1852), Examen médico del siguiente pasage de Chateaubriand en sus «Mémoires d'outre-tombe»; 'Lejos de mi cadáver la sacrílega autopsia . . . '; o sea Consideraciones sobre el impulso y carácter comunicados por la anatomía a la medicina moderna. Memoria, Barcelona, Imprenta y Librería Politécnica de Tomás Gorchs, p. 5.

12 Para las traducciones de Chateaubriand, véase MONTESINOS, J. (1955), Introducción a una historia de la novela en España en el siglo XIX, Madrid, Castalia, pp. 210-214.

13 Chateaubriand, F-R. (1910), Mémoires d'outre-tombe, vol. 1, ed. Edmond Biré, París, Librairie Garnier Frères, p. lv.

14 Pi y Molist (1852), p. 3. 
Hasta los hombres más privilegiados a quienes el Criador ha dotado de una comprensión universal, no podrán ejercerla cual conviene, si cuando se ocupan de una materia, no se despojan en cierto modo de sí mismos, para hacer obrar las facultades que mejor se adaptan al objeto de que se trata ${ }^{15}$.

Al aludir a ese despojarse de uno mismo, Balmes parece crear un marco en el que situar el examen que, de este asunto, Pi y Molist lleva a cabo de manera presumiblemente desinteresada. El ideal de objetividad se basa en un desnudamiento simbólico del ser, en otras palabras, en un tipo de autopsia que paradójicamente deja al descubierto, no al ser en realidad, sino al tema en cuestión: es decir, la autopsia. Pi y Molist volverá a referirse al filósofo católico del siglo XIX más adelante, en el contexto de la admiración que profesa Balmes hacia una autoridad religiosa si cabe aun más imponente, la Introducción al Símbolo de la Fe de Fray Luis de Granada, en la que el elogio que hace el buen clérigo del cuerpo humano como una maravilla de la acción divina sirve como justificante de los beneficios humanitarios de la autopsia ${ }^{16}$.

Pi y Molist muestra una clara inquietud por disociar de la práctica de la autopsia la acusación de sacrilegio que tradicionalmente se le hacía. Dice: «¿Por qué esa tenaz prevención contra la abertura de un cadáver, practicada con la reverencia que se le debe por lo que fue su anterior estado?» ${ }^{17}$. Y un poco después: «La abertura del cuerpo de un difunto con el exclusivo fin del estudio ¿entraña lesión, violencia o desprecio de cosa sagrada?» ${ }^{18}$. La afirmación retórica con que concluye deja claro que, para él, ofrecer el propio cuerpo a la ciencia está imbuido de connotaciones de sacrificio religioso: «iSabe Dios si mis pobres restos llegarán a prestar un servicio de tanta importancia!» ${ }^{19}$.

En esta narrativa de tipo heroico, en que la ciencia marcha hacia el conocimiento para aliviar el futuro sufrimiento humano, el modelo médico de Pi y Molist resulta ser, como es lógico, otro doctor: Francisco Salvá y Campillo. En el testamento de Salvá, que había legado su cuerpo a la ciencia, se puede leer:

15 Balmes, J. (1956), El Criterio, Madrid, Espasa-Calpe, p. 80.

16 Es importante señalar, sin embargo, lo que dice Laín Entralgo: «Muy otro es el propósito de Fray Luis de Granada. No pretende que sus elementales descripciones anatómicas sean útiles al médico ni que satisfagan la curiosidad intelectual del menesteroso de saber. Más modesta —o más ambiciosamente, no sé — aspira a despertar en sus lectores dos sentimientos sucesivos: el asombro, primero; luego, la devoción»; véase LAÍN ENTRALGO, P. (1946), La antropología en la obra de Fray Luis de Granada, Madrid, Consejo Superior de Investigaciones Científicas, pp. 214-215.

17 Pi y Molist (1852), p. 9.

18 Pi y Molist (1852), p. 10.

19 Pi y Molist (1852), p. 38. 
Si la disección de mi cadáver puede servir de instrucción pública, [...] quiero absolutamente y mando que, lejos de oponerse a ella, la faciliten en mi habitación a los Profesores que la pidan, suministrándoles la ropa necesaria para la decencia y perfección de aquella; permitiéndoles también extraer de mi cadáver las partes que se necesiten para un gabinete patológico; y pagando hasta diez y seis duros de mi dinero la preparación necesaria para la conservación de lo que se extrajere, conducente a la instrucción patológica ${ }^{20}$.

Salvá asimismo solicitó que, tras la autopsia pública, su cuerpo fuera trasladado al cementerio:

entre los cadáveres de aquella santa casa y en el mismo carro [...] Como he hecho mis delicias de estar en vida entre los enfermos y muertos de aquel asilo de infelices, no me disgustará su compañía después de muerto, y ser tratado como uno de ellos 21 .

Esta extraña superposición de sacrificio médico y espiritual en Salvá y Campillo es también característica de Pi y Molist, cuyo argumento retórico oscila continuamente entre dos estrategias discursivas: la positivista-médica y la cristiano-romántica. Por una parte, sigue a Chateaubriand al enfatizar el misterio último de la vida humana, que nunca será revelado sin importar el número de autopsias que se le realicen. Por otra, insiste en la pura cualidad física del cuerpo humano: habla de «la sustancia cerebral y blanda» y del corazón como «esencialmente musculoso», y prosigue describiendo ambos órganos desde una distancia clínica ${ }^{22}$. Dos páginas más adelante, sin embargo, escribe: «El solo sentido común indica lo absurdo de la investigación que tuviera por objeto descubrir en el cadáver aquel agente poderoso, la vida, cuya ausencia lo ha constituido en el estado de tal» ${ }^{23}$.

A lo largo de su ensayo, Pi y Molist combina el lenguaje de lo clínico con el del romanticismo; así,

20 Cit. en Pi y Molist (1852), p. 26. Véase también JANER, F. (1832), Elogio histórico del Dr. D. Francisco Salvá, Barcelona, Imprenta de Joaquín Verdaguer, para una explicación más detallada de las contribuciones de Salvá y Campillo a la medicina, que incluían arriesgar su propia vida en 1821 para atender a víctimas de la fiebre amarilla en Barcelona. El cuerpo de Salvá, fallecido en 1828 de una hemorragia cerebral a la edad de 76 años, fue efectivamente sometido a autopsia tal como solicitó.

21 Cit. en Pi y Molist (1852), pp. 26-27.

22 Piy Molist (1852), pp. 30-31.

23 Pi y Molist (1852), p. 33. 
la Anatomía patológica [...] manifiesta las misteriosas relaciones que guardan entre sí los órganos de la economía humana [...] No bien se afecta súbita y hondamente una parte interesante, la economía entera se conmueve, se trastorna y parece obedecer una nueva ley [...] órganos que en el estado normal daban apenas señales de existencia despliegan una vitalidad prodigiosa; establécense de improviso mil relaciones desconocidas ${ }^{24}$.

El cuerpo humano es, por encima de todo, una estructura que debe explicarse por medio de la relación entre sus partes, u organización, y por los cambios materiales «como razón suficiente de todos los fenómenos» ${ }^{25}$. Y, sin embargo, esta organización es igualmente un misterio, pues posee «misteriosas relaciones» que nos recuerdan no solo a las creencias católicas de Pi y Molist, sino también a su cercanía al romanticismo y, por supuesto, al propio Chateaubriand. Este es aparentemente el débil lazo del que saca provecho el doctor barcelonés para defender el tema de la autopsia en particular y, más allá de ello, legitimar institucional y profesionalmente la medicina clínica dentro de España. Para este fin, se pregunta incluso si una persona tiene derecho a decidir no conceder su cuerpo a tan inestimable servicio a la medicina y la humanidad y declara asimismo que la realización de disecciones debe ser dejada a la discreción y buen juicio de los doctores ${ }^{26}$. Su objetivo es discutir el evidente ataque de Chateaubriand contra el sacrilegio de la autopsia.

Lo que Pi y Molist no hace en su análisis es situar en contexto las palabras del romántico francés, que son parte del Avant-propos de sus voluminosas Mémoires d'outre-tombe. Las memorias de Chateaubriand operan, tanto en su espíritu como en su propósito, a modo de resurrección: «je désirerais pouvoir ressuciter à l'heure des fantômes pour en corriger les épreuves: les morts vont vite» («Desearía poder resucitar a la hora de los fantasmas para corregir las pruebas: los muertos van deprisa») ${ }^{27}$. Su texto es su última voluntad y testamento, escrito desde dentro y más allá de su tumba: es, en efecto, su propio monumento funerario, un monumento que ahora está obligado a «hipotecar», dice él, por necesidades financieras ${ }^{28}$. Publicar se convierte en una forma de sacrilegio, ya que expone (y «vende») «ces voix qui ont quelque chose de sacré, parce qu'elles sortent du sépulcre» («estas voces que tienen algo de

\footnotetext{
24 Pi M Molist (1852), p. 33.

25 Pi M Molist (1852), p. 24.

26 Pi y Molist (1852), pp. 6, 36.

27 Chateaubriand (1910), «Préface testamentaire», p. xlix.

28 Chateaubriand (1910), «Avant-propos», p. li.
} 
sagrado, porque salen del sepulcro») ${ }^{29}$. Las Mémoires están destinadas a conmemorar a los muertos, mantenerlos en vida - ello incluía a todo aquel a quien Chateaubriand conocía, incluyéndose a sí mismo - por medio de un segundo enterramiento dentro del texto-sepulcro del escritor. La postura profundamente ambivalente y conflictiva de Chateaubriand hacia su escritura y publicación está - literal y figuradamente hablando - llena de la presencia de espectros. Tiene el autor plena conciencia de lo gravemente irónica que llega a ser la naturaleza espectral de su empresa: sus palabras resucitarán a los muertos pero solo como voces, como figuras de ausencia, a modo de una prosopopeya frustrada ${ }^{30}$. Los muertos son sagrados aunque secundarios en la medida en que son presencias derivadas que ya no pueden encarnarse por completo. Al mismo tiempo, es obvio que Chateaubriand obtiene un placer estético y afectivo al reanimar a los muertos.

Su dilema se hace contundentemente claro en el último párrafo del Avantpropos, del cual Pi y Molist extrae el pasaje que luego discute. Pi y Molist, sin embargo, no explica que el escritor francés estaba hablando sobre una circunstancia hipotética. De morir lejos de casa, escribía Chateaubriand,

je souhaite que mon corps ne soit rapporté dans ma patrie qu'après cinquante ans révolus d'une première inhumation. Qu'on sauve mes restes d'une sacrilège autopsie; qu'on s'épargne le soin de chercher dans mon cerveau glacé et dans mon cœur éteint le mystère de mon être. La mort ne révèle point les secrets de la vie. Un cadavre courant la poste me fait horreur; des os blanchis et légers se transportent facilement: ils seront moins fatigués dans ce dernier voyage que quand je les traînais ça et là chargés de mes ennuis ${ }^{31}$.

Al citar de manera selectiva partes del Avant-propos, Pi y Molist hizo caso omiso del contexto personal de las palabras de Chateaubriand - la preocupación

29 ChateAubriand (1910), «Avant-propos», p. liii.

30 Para más información de la importancia de la prosopopeya, véase FERNÁNDEZ, L.M. (1994), De la 'poética de los muertos' al paisaje trascendente: Una aproximación a las relaciones entre Chateaubriand y Bécquer, Anales de Literatura Española (Alicante), 10, pp. 81100; y DE MAN, P. (1979), Autobiography as De-facement, MLN, 94, pp. 919-930.

31 «Deseo que mi cuerpo no sea devuelto a mi patria hasta que hayan pasado cincuenta años desde mi enterramiento. Que mis restos se salven de una sacrílega autopsia; que se evite la molestia de buscar en mi cerebro congelado y en mi corazón apagado el misterio de mi existencia. La muerte no revela los secretos de la vida. Un cadáver por correo me horroriza; huesos blanqueados y ligeros se transportan fácilmente: estarán menos fatigados en este último viaje que cuando yo los arrastraba de aquí para allá cargados con mis achaques», CHATEAUBRIAND (1910), «Avant-propos», pp. liv-lv. 
sobre los preparativos de su propio enterramiento- y de su importancia figurativo-simbólica ${ }^{32}$. La resurrección corporal descrita por Chateaubriand también refleja, al igual que el texto de Pi y Molist, la edad de la medicina clínica (el Avant-propos data de 1846). El horror mostrado ante la contemplación del deterioro de su propio cuerpo en el viaje de retorno a casa en Saint-Malo y el deseo de devolver huesos limpios y ligeros pueden relacionarse con el énfasis en voces y presencias fantasmales de los muertos, las cuales hablan por sí solas del tópico romántico de la «hermosa muerte» ${ }^{33}$. Así, por un lado, estas voces son meras figuras de ausencia; por otro, esperar o desear algo más puede habérsele figurado a Chateaubriand como un metafórico robo de tumbas. En Gran Bretaña, los ladrones de tumbas eran también llamados «resurreccionistas» (resurrectionists o resurrection men), cuyo ajetreado negocio de proveer de cadáveres a los hospitales universitarios y a los anatomistas para sus disecciones era bien conocido ${ }^{34}$.

Sin dejar de lado el rechazo de raigambre católica que siente Chateaubriand por la autopsia como sacrilegio, también sugeriría yo que su obsesión por el enterramiento y el renacer de los muertos es simplemente la otra cara de la autopsia. El fetichismo por las partes corporales que supone la autopsia es una suerte de romanticismo a la inversa, es decir, una preocupación extrema por la conmemoración, devolviendo a los muertos de nuevo a la vida. El desfase o cruce transgresivo entre la vida y la muerte, entre la carne y el espíritu, el enterramiento y la resurrección, la autopsia y la preservación, apunta a un desdibujamiento de categorías y fronteras. Este movimiento sugiere una incursión en el territorio de lo siniestro, en el que un cuerpo doble es deseado pero también temido. Quizás no sea accidental que Chateaubriand hallara imposible volver a su ciudad natal de Saint-Malo, aunque hablara de ello constantemente ${ }^{35}$. No solo estaba allí su infancia, sino también la que habría de ser su sepultura, como si Chateaubriand hubiera concertado para su propio doble - su cuerpo sin vida - fundir en una anticipación freudiana lo familiar y lo desconocido, das heimliche y das umheimliche, hogar y sepultura ${ }^{36}$.

32 Para más detalles sobre las prolongadas dificultades que hubo de soportar Chateaubriand para adquirir el terreno de su tumba, véase el Apéndice de la edición de Biré, vol. 1, pp. 442-447.

33 Sobre la «hermosa muerte» véase ARIÈs, P. (1991), The Hour of Our Death, Nueva York, Oxford University Press, pp. 409-474.

34 Para la historia de estos ladrones de tumbas, véase COLE, H. (1964), Things for the Surgeon. A History of the Resurrection Men, Londres, Heinemann.

35 Chateaubriand (1910), vol. 1, p. 444.

36 Véase Freud, S. (1953), The 'Uncanny' (1919). En Collected Papers, vol. 4, 7. impr., Londres, Hogarth Press, pp. 368-407. 
De manera similar, Pi y Molist muestra una gran preocupación por no «matar» el cuerpo y lucha por reconciliar las creencias católicas con los principios de la medicina para producir un cadáver que es fisiológicamente específico y, sin embargo, extrañamente siniestro. De esta manera, el cuerpo de Salvá y Campillo se sacraliza. Pero, además, la investigación sobre la patología de los muertos conduce a otro tipo de monumentalización en el texto de Pi y Molist que no es la tumba de Chateaubriand, sino otra estructura: la medicina misma como «un grandioso edificio con sola una puerta de ingreso, la Anatomía» ${ }^{37}$. La preocupación por el sufrimiento de la humanidad y el deseo de conocer se transforman ambos en materiales para construir otra narrativa, esto es, para sentar por completo la legitimidad de la medicina moderna en España.

La práctica de la autopsia sirve aquí como figura y como trampolín para la profesionalización de la medicina clínica en la España del siglo XIX. A comienzos de este siglo, Juan Fourquet, que tenía ciertas tendencias místicas, veía la disección como si fuera «una serie de verdades reveladas», según señala otro doctor, Alejandro San Martín ${ }^{38}$. Hacia mediados de siglo, puede observarse en el texto de Pi y Molist que la disección como revelación es aún muy importante, pero el cuerpo se está convirtiendo ahora en algo secularizado y profesionalizado. La figura clave en la medicina clínica española de esta época fue Pedro Mata, a quien se le atribuye a menudo el haber introducido la medicina forense en España con sus enseñanzas, su práctica y su Tratado de medicina legal (1846). Luis Simarro, en su relación sobre la vida profesional y la influencia de Mata, presenta un vínculo entre, de un lado, la práctica de la disección de esta figura pionera y, de otro, la profesionalización de la medicina en España. Tras haber estudiado medicina con Orfila en París, Mata quiso establecer una Morgue similar a la institución francesa para dar lecciones prácticas de anatomía y patología. Sin embargo, se topó con un obstáculo insalvable. Como expone Simarro

[Mata] tropezó con un pequeñito inconveniente, una de las llamadas cosas de España, y fue que los cadáveres depositados en las dependencias del hospital pasaban allí seis u ocho días, antes de que se pudiera conseguir del juez el permiso para acometer el estudio de ellos. Por tal modo que venía a resultar completamente inútil toda investigación; y Mata no tuvo más remedio que resignarse contra su convicción y su deseo a explicar medicina legal retóricamente ${ }^{39}$.

37 Pi y Molist (1852), p. 37.

38 Cit. en San Martín, A. (1886), 20. ${ }^{a}$ Conferencia. En La España del siglo XIX, Ateneo, Curso de 1885-1886, vol. 2, Madrid, Librería de Don Antonio San Martín, p. 256.

39 Simarro, L. (1886), 25. ${ }^{a}$ Conferencia. En La España del siglo XIX, Ateneo, Curso de 1885-1886, vol. 2, Madrid, Librería de Don Antonio San Martín, p. 548. 
En el párrafo siguiente, Simarro aclara que, para él, los heroicos esfuerzos de Pedro Mata por crear en España un espacio para la medicina moderna fueron decisivos en la profesionalización de esta como institución:

se esforzó en hacer comprender a sus contemporáneos que estas cuestiones no son, como pretenden las gentes, de sentido común, sino de ciencia, que es necesariamente algo superior al saber vulgar y que no basta, por tanto, tener sentido común para resolver las cuestiones de Medicina ${ }^{40}$.

Como Pi y Molist en 1852, Simarro, uno de los grandes institucionistas liberales de finales de siglo, estaba resuelto a fijar los parámetros de la medicina moderna española otorgando a los hombres de ciencia facultades y formas de conocimiento especiales que los harían claramente superiores sacralizados, si se quiere- con respecto al resto de la población. En una palabra, profesionales.

La forja de una cultura profesional a través de la práctica de la autopsia está también patente en mi segunda narrativa del siglo XIX: la historia del doctor Velasco y la fundación de la antropología en España. En esta narrativa, como en la anterior, la profesionalización es verdaderamente parte de una narrativa humanitaria más amplia modelada por una imaginación católica. Pedro González Velasco (1815-1882) fue un hombre hecho a sí mismo y de origen humilde, que pasó de ser cuidador de cerdos a pregonero y, más tarde, sirviente en un hogar noble, para convertirse quizás en el más destacado disector de la España del siglo XIX. Según sus propios cálculos, se estima que llevó a cabo más de 8.000 autopsias durante su vida profesional y que hizo gran cantidad de trabajos anatómicos altamente considerados ${ }^{41}$. Progresista

40 Simarro (1886), p. 549.

41 Mis fuentes para esta información pueden encontrarse en PULIDO Y FERNÁNDEZ, A. (1894), El doctor Velasco, Madrid, Est. Tip. de E. Teodoro, y RoMERo DE TEJADA, P. (1992), Un templo a la ciencia. Historia del Museo Nacional de Etnología, Madrid, Ministerio de Cultura; véase también Puig-Samper Mulero, M.A. (1982), El Doctor Pedro González de Velasco y la antropología española en el siglo XIX, Asclepio, 34, pp. 327-337, y ArQuiOLA, E. (1981), Anatomía y antropología física en el positivismo español, Asclepio, 33, pp. 3-22. Para una versión ficcionalizada de Velasco, véase SENDER, R. (1967), La hija del doctor Velasco. En La llave y otras narraciones, Madrid, Emesa. Para más ejemplos de reconstrucciones literarias - y de otro tipo- de la historia de Velasco, veáse también MARTIN-MÁRQUEZ, S. (2003), Anatomy of a Black Legend: Bodies of Cultural Discourse and Madrid's National Museum of Anthropology, Journal of Spanish Cultural Studies, 4 (2), pp. 205-222, según la cual dicha historia transforma a Concha en una «'mujer pública' mientras circula por narra- 
desde el punto de vista político y católico practicante ${ }^{42}$, Velasco estaba obsesionado con el estudio de la anatomía. Durante la ceremonia de inauguración de su Museo Antropológico (actualmente el Museo Nacional de Etnología) en 1875, afirmó: «A la ANATOMÍA debo lo poco que sé y lo más poco que valgo ${ }^{43}$. Velasco llamó a su sala de disecciones «el palacio encantado de la vida formado con los despojos de la muerte $\rangle^{44}$.

La relación que el mismo Velasco ofrece de su vida profesional puede leerse como una versión secularizada de la vida de un mártir. En su esfuerzo por crear una disciplina legítima de estudios anatómicos, lo acosaban las envidias mezquinas de sus colegas, penas y privaciones, la apatía del gobierno, etc., pero, como él mismo nos cuenta, no abandonó. La Reseña histórica de los trabajos anatómicos del doctor don Pedro González Velasco de 1864, a la cual me remito, nos presenta a un hombre incansable, tenaz y que sufría, hasta cierto punto, de manía persecutoria:

En este largo número de años, no he tenido un solo día de tranquilidad; todo ha sido zozobra, trabajo, gasto y ansiedad. En cuatro o cinco meses, todo ha sido plácemes y triunfos para mi comprofesor. Sea: resignémonos con la desgracia. Hay también sus goces en las derrotas. La mía es puramente oficinal, inquisitorial ${ }^{45}$.

Habla de proyectos vagos y grandiosos: «no cejaré: mi plan es infinitamente más vasto que lo que se ve y se descubre hoy. Mi plan va mucho más allá». Advierte a colegas poco favorables a él y a quienes claramente considera sus enemigos, de que conoce las intrigas urdidas contra él:

ciones teñidas de matices necrófilos que evocan la más decadente de las prácticas y pueden incluso inspirar pánico racial». Velasco, dice ella, «no puede hacer nada por controlar la propia fuerza narrativa de Concha» (p. 220). Todas estas historias, sin embargo, surgieron después de la muerte de Velasco, por lo que el «control» del buen doctor es un asunto discutible. Es más, el análisis de Martin-Márquez intenta explicar las acciones de Velasco dependiendo en exceso de elaboraciones literarias posteriores de la leyenda de Velasco, elaboraciones estas que «hacen circular» el cuerpo de Concha.

42 Perera y Prats, A. (1967), La vida del Dr. Velasco, creador de un museo, Anales de la Real Academia Nacional de Medicina, 84, pp. 11-12.

43 Pulido y Fernández, A. y González Velasco, P. (1875), Discursos leidos en la Apertura del Museo Antropológico y Escuela Libre del Dr. Velasco, Madrid, Imprenta, Fundición y Estereotipia de D. Juan Aguado, p. 49.

44 GonzÁlez Velasco, P. (1864), Reseña histórica de los trabajos anatómicos del doctor don Pedro González Velasco escrito por él mismo en sus últimos viajes al estranjero [sic], Madrid, Imprenta de Manuel de Rojas, p. 7.

45 GonZÁlez Velasco (1864), p. 41. 
Yo sí tengo mis apuntes, llevo y guardo notas relativas a las acciones, a los hechos que han tenido lugar y se enlazan con este asunto; tengo hasta el día, el mes, el año, el motivo aparente o real de lo que yo haya apreciado entonces como contrario a mis proyectos, todo lo tengo apuntado, de todo tengo datos ${ }^{46}$.

Y escribe: «Yo tengo enemigos muy poderosos que no quieren ver ni reconocer la verdad [...] Soy el Colón ante los sabios doctores de Salamanca» (p. 54) ${ }^{47}$.

¿Qué pudo haber trastornado tanto a Velasco como para producir este texto intensificado y casi histérico? En una publicación sobre el Museo Nacional de Etnología, Pilar Romero de Tejada intenta combatir la leyenda de un doctor Velasco enloquecido y señala que fue efectivamente perseguido por la Iglesia y sus celosos e incomprensivos colegas. Además, destaca merecidamente sus sólidas y abundantes contribuciones al estudio de la anatomía y la antropología. Pero minimiza lo que se convirtió en la mayor tragedia de su vida: la muerte en 1864 de su única hija, Concha, a los 15 años de edad. Velasco perdió el control: agobiado por la culpa de haber recetado el medicamento erróneo para la fiebre tifoidea que padecía, él la conmemoró en su muerte ${ }^{48}$. Él mismo emprendió la tarea de embalsamarla. Luego, se rodeó de cuadros, fotografías, un busto de ella y objetos que habían pertenecido a Concha. Como decía un contemporáneo suyo, «multiplic[aba] las facciones de su hija» con todos estos esfuerzos ${ }^{49}$. Aprendió a tocar el piano para interpretar la música favorita de Concha y, finalmente, once años después de su muerte, recibió la autorización para desenterrar su cuerpo, con la idea de ubicarla en el recién inaugurado museo que él había creado y, de este modo, mantenerla siempre cerca.

Me remito aquí a su amigo y colega, el doctor Pulido, quien fue testigo de la escena:

Fijábase nuestra vista en aquella cabeza, desnuda y limpia como bola de marfil, que durante la vida había vestido abundante y perfumada cabellera negra; en aquella pálida

46 GonZÁlez Velasco (1864), p. 53.

47 En la posterior creación galdosiana del personaje de Maxi en su obra maestra de la ficción realista, parece resonar con eco la extraordinaria voz que proviene de estas páginas del doctor Velasco. Véase PÉREz GALdós, B. (1983), Fortunata y Jacinta, 2 vols., ed. Francisco Caudet, Madrid, Cátedra (orig. 1886-1887).

48 Véase ARIÈs (1991), parte IV, para la nueva obsesión romántica por la muerte ajena, que incluía el moderno culto a las tumbas y cementerios en el siglo XIX.

49 Prieto y PRieto, M. (1875), El Museo Antropológico, La Ilustración Española y Americana, 19 (17-19), p. 307. 
frente, tras de la cual se habían formado los misterios insondables de la idea; en aquellos ojos apergaminados, rugosos y hundidos en el fondo de las órbitas, que habían brillado con el fuego de la mirada; en aquellas mejillas, entonces negruzcas, que antes tiñeron el delicado color rosa de la vida y el hermoso carmín del pudor; y en aquellos labios finos, secos y fríos, de los cuales tantas veces habían manado dulces palabras, tiernas sonrisas, alegres carcajadas y cariñosos ósculos para su desgraciado padre.

Todo se conservaba allá perfectamente, con restos de juventud y de belleza; por extraña suerte, podía el Dr. Velasco reproducir el violentísimo dolor del terrible día ante el espectáculo del cuerpo de su hija que parecía recién muerto ${ }^{50}$.

Tras cortar su mortaja (de hecho, un hábito religioso), Velasco se sumió en un silencio contemplativo; luego, procedió a examinar y tocar sus miembros, exclamando «con acento extraño: “¡Todavía están flexibles! ¡Podría sentarse!" $\gg{ }^{51}$. Pero esto no fue todo: durante el verano, permitió que fuera momificada y después llamó a una modista. El doctor Pulido escribió:

En el otoño del 75 y cuando lo creyó conveniente, dispuso que una modista vistiese [los despojos] con precioso traje de raso blanco, calzó sus manos y pies con elegantísimos guantes y zapatos de raso, colocó pulseras en sus muñecas, cubrió su cabeza con peluca y manchó su rostro con colorete; en una palabra, procuró por retocados artificios disimular todo lo posible la muerte, para dar apariencias de cuerpo dormido a los restos de su hija, ya entonces, y por la evaporación, mucho más desfigurados 52 .

Su esposa, sin embargo, no dejó que sentara el cuerpo a la mesa para comer. Finalmente, Velasco colocó a Concha en un enorme estuche de cristal, convirtiendo el museo en una suerte de capilla ad hoc ${ }^{53}$. Tras varios meses y habiendo recobrado el juicio, se deshizo del vestido blanco, los elegantes zapatos y guantes, la joyería, la peluca y el maquillaje, vistiendo de nuevo el cadáver con un simple hábito religioso. Después de la muerte de Velasco en 1882, su viuda trasladó el cuerpo de Concha al Cementerio de San Isidro mientras que el de Velasco, asimismo depositado en el museo - parte del cual sirvió al doctor de residencia y cuarto de disecciones-, fue de nuevo enterrado más tarde en otro lugar.

Claramente, la hija de Velasco estaba destinada a ser la pieza central del museo, el cual, como era característico de este tipo de museos en la época,

\footnotetext{
50 PUlido y FERNÁNDEZ (1894), pp. 64-65.

51 Pulido Y FERNÁNDEZ (1894), p. 65.

52 Pulido Y FERNÁNDEZ (1894), p. 66.

53 PULIDO Y FERNÁNDEZ (1894), p. 66.
} 
estaba formado por colecciones ampliamente heterogéneas, organizadas según un particular «ordenado amontonamiento» ${ }^{54}$. Pulido lo describe como un

almacén solemne y carnavalesco donde el cráneo corroído y la esmaltada concha, el girón de vestido y la momia pestilente, el guijo de antigua cerámica y la carne humana desecada, la moneda antigua y el hacha celta, el fósil y el libro, el feto monstruoso y el ave de bellos colores, el mineral y la planta..., todo lo que arroja de sí el taller inmenso y siempre activo de la vida, se mezcla, se baraja, se confunde, llenando vitrinas, y tableros, y armarios, y salones ${ }^{55}$.

En otras palabras, Concha se convirtió en un objeto de coleccionista, aunque muy especial ${ }^{56}$. Los esfuerzos de Velasco por preservarla y exhibirla sugieren un paralelo entre su «reproducción» y el proceso de elaboración de modelos anatómicos de cera que sirven de ayuda en las disecciones. La intensidad y la pasión que el doctor Velasco invirtió en este rarísimo proyecto apunta a una percepción de lo real sumamente personal y, sin embargo, ritualizada. Esta percepción se manifiesta a sí misma como un modo particular de asirse a la experiencia materialmente a través de la reproducción. El resultado, por supuesto, no es la vida, ni el monstruo de Frankenstein ni la escultura de Pigmalión, sino un museo de cera hecho carne. Pulido consideraba el museo de Velasco como una

54 PULIDO Y FERNÁNDEZ (1894), p. 75.

55 PULIDO Y FERNÁNDEZ (1894), p. 74.

56 MARTIN-MÁRQUEZ (2003), p. 208, también nota que Concha fue «mostrada como un objeto estético dentro de una valiosa colección de curiosidades». Martin-Márquez adopta un acercamiento a la historia de Velasco distinto al mío, intentando establecer un vínculo algo dudoso de asociaciones entre raza, clase, la leyenda negra, Velasco y su hija. Según ella, al «transformar a su hija fallecida en una "santa", Velasco procura conjurar las amenazas de la degeneración, asociada en particular con las clases privilegiadas» (p. 220). Sin embargo, la degeneración de la clase alta que ella describe proviene de opiniones expresadas por Manuel Prieto («Museo Antropológico») y no por el propio Velasco (Martin-Márquez, pp. 211-212). Además, las palabras délficas nosce te ipsum («conócete a ti mismo») escritas sobre la entrada del museo son más bien tradicionales, habituales en este tipo de contexto y, por tanto, difícilmente orientadas a «poner al descubierto las horrendas consecuencias de la degeneración de la clase alta española a los propios miembros de esa clase» (Martin-Marquez, p. 212). Los ejemplares patológicos del museo también simbolizan la degeneración en este argumento. Desgraciadamente, la mayoría de estas muestras, si no todas, provenían de pacientes de hospitales públicos, es decir, prostitutas, mendigos y pobres (véase GonZÁLEZ VELASCO [1864], pp. 5051). No hay pruebas que demuestren su tesis. Asimismo, los ciudadanos pertenecientes a las clases medias, y no únicamente los de las clases altas, acudían también a los museos. ¿Pretendía Velasco acusarlos también? Probablemente no. Los museos del siglo XIX estaban destinados a instruir, no a condenar. 
pasión de pasiones que se alimenta y crece, como flor de cementerio, con el recuerdo de una hija muerta; engendro híbrido de la ambición; fruto abigarrado y fenomenal de un plan monstruo; amasijo de virtudes y flaquezas; creación magna como nacida al soplo turbulento de un frenesí y al santo fuego de una inspiración providencial ${ }^{57}$.

Velasco sabía lo que era la muerte física. La había diseccionado miles de veces. Y, aun así, se había negado a aceptar la muerte de su hija. La figura momificada de Concha se convirtió en su propio doble corporal, una forma de lo siniestro que el doctor Velasco intentó trocar en algo familiar y vivo, enfatizando de esta manera inconscientemente la recurrencia freudiana de algo familiar y antiguo (das heimliche) que había sido reprimido (aquí, enterrado) y transformado en algo extraño (das unheimliche). Si la autopsia abre el cuerpo a la mirada, y lo desmiembra para indagar en él, la momificación lo cierra, secando y encogiendo sus partes para conservar el cuerpo en un estado de animación fingida. Sin embargo, tanto la autopsia como la momificación, al fijarse en las partes del cuerpo, tratan a este como un fetiche. La autopsia se ocupa de partes que más tarde son a menudo recogidas y conservadas. Los modelos anatómicos de cera, como, por ejemplo, el de una mujer cuyo vientre se abre para mostrar un feto en su interior, u órganos específicos, enfermos o sanos, debían parecer tan verosímiles como fuera posible - en buena medida como la reanimación de la hija de Velasco - y, aun así, conservar inmutables los órganos en cuestión, en el nivel de una experiencia artificial, de segunda mano ${ }^{58}$.

Estos dos procedimientos - la disección y la momificación - son figuras de ausencia. Fijan la muerte para siempre, y sin embargo nos recuerdan a lo que alguna vez estuvo vivo; son portadores de un rastro, como fantasmas de la vida, y marcan el espacio entre la vida y la muerte, borrando de este modo fronteras, como observa Michelle Bloom al respecto de las figuras de cera. Son semejantes a «figuras de cera [que] encarnan lo real y estimulan lo ima-

57 Pulido y FernáNDEZ (1894), pp. 73-74.

58 Véase también GonZÁleZ-CrUSSI, F. (1995), Suspended Animation. Six Essays on the Preservation of Bodily Parts, Nueva York, Harcourt Brace and Company, pp. 69-87, para más información sobre la historia de los modelos anatómicos de cera. Sobre el embalsamamiento, véase PuSALgas y GUERRIS, I.M. (1861), Métodos de embalsamamiento por tiempo definido e indefinido, mutilando lo menos posible los órganos del cadáver, Barcelona, Imprenta de José Tauló, p. 5, en la que anota que esta práctica requería autorización civil y eclesiástica; y también GARCÍA, J. (1981), El embalsamamiento de cadáveres, una antigua costumbre que comienza a ser frecuente en España, El País, 26 de agosto. 
ginario simultáneamente ${ }^{59}$. No resulta sorprendente que estas fascinantes muestras anatómicas del siglo XIX fueran igualmente atracciones turísticas y estuvieran consideradas por muchos como signos de progreso cultural y científico. Adolfo de Castro aporta detalles abundantes de una muestra médica de este tipo en Cádiz, reduplicando verbalmente por medio de una enumeración caótica el popurrí de colecciones museísticas del siglo XIX ${ }^{60}$.

Como el cuerpo sacralizado del doctor Salvá en la memoria de Pi y Molist, y las voces del más allá de Chateaubriand, la autopsia y la conservación del cuerpo y sus miembros viven con una presencia espectral, la de la reanimación, esto es, el regreso de los muertos. Los muertos pueden ser, bajo determinadas circunstancias, el inconsciente o un yo desdoblado que el individuo no conoce. Así, Henry Maudsley recoge en The Pathology of Mind (1886) texto muy influyente en España- el sueño sobre una autopsia de la siguiente manera:

En varias ocasiones he tenido un sueño muy vívido en el que yo participaba en el examen post-mortem de un cuerpo que volvía a la vida y tranquilamente se incorporaba a una postura sedente sobre la mesa en la que yo trabajaba. En una ocasión, cogía un mazo de madera y le golpeaba en la cabeza con todas mis fuerzas; en otra ocasión, introducía mi mano en su pecho y le arrancaba el corazón; pero ninguna de estas acciones desesperadas parecía hacerle morir o comportarse como debiera un cadáver. En todos los casos, hasta donde puedo recordar, existía el mismo sentimiento indescriptible de perplejidad y aprehensión, junto con una resolución de evitar a cualquier precio las consecuencias de disecar un cuerpo vivo; tenía, además, un fuerte sentido de represión personal o humillación que no experimentaba en la vida real desde la escuela ${ }^{61}$.

Por razones de espacio, no me es posible llevar a cabo un detallado análisis de este sueño tremendamente evocador, pero distintas narrativas lo recorren: miedo a la muerte, miedo a lo inconsciente, a algo reprimido, miedo al entierro prematuro, a la castración, al canibalismo, miedo a los muertos mismos. Pero Maudsley no hace demasiado hincapié en su propio sueño, atribuyéndolo a «algún estado de malestar intestinal» ${ }^{62}$. Su negación a autoanalizar-

59 Bloom, M. (2003), Waxworks. A Cultural Obsession, Minneapolis, University of Minnesota Press, pp. xi, 160.

60 Véase De Castro, A. (1859), Manual del viajero en Cádiz, Cádiz, Imp. de la Revista Médica, pp. 88-94.

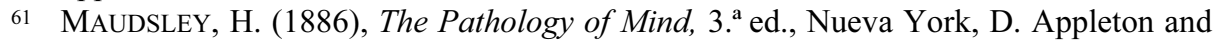
Co., p. 33 .

62 Maudsley (1886), p. 73. 
se puede estar conectada a sus posturas anti-católicas y su desprecio de las prácticas confesionales, a las que consideraba tortuosas, injuriosas y conducentes, según él, a la locura o el pecado a través de «un auto-sentimiento exacerbado, arraigado en la pasión sexual» ${ }^{63}$.

Si bien Maudsley, de familia protestante, reconoce una consciencia dual en el sueño, es reacio a sacralizarla, es decir, a convertir ese otro, ese yo soñado, en un fantasma o un espectro. Velasco no solo libera su fantasma, sino que también le concede una personificación total y la muestra al público. El cuerpo reanimado de Concha está insertado simbólicamente, como una reliquia católica, en una compleja narrativa en que humanitarismo y profesionalismo se interconectan. El cuerpo de Concha tuvo que ser mostrado públicamente en el museo porque las ambiciones de Velasco en el campo de la antropología, en aquella altura, habían incurrido ya en transgresión, mezcladas con un amor obsesivo e inconscientemente incestuoso por su hija. El fetiche y la reliquia son difíciles de separar en este caso. Velasco, asimismo, ya había envuelto antropología y anatomía en un discurso fuertemente teñido de orgullo nacional y fervor humanitario ${ }^{64}$. El museo estaba destinado a ser un proyecto nacional, concebido simultáneamente como un instituto de enseñanza, un lugar de ciencia y un beneficio a la humanidad ${ }^{65}$.

Al mismo tiempo, el estrecho vínculo entre el estudio de la anatomía y la creciente disciplina de la antropología, no solo en España sino también en

63 MAUdSLey (1886), pp. 144-145.

64 Un admirador del doctor Velasco, Manuel Prieto y Prieto (1875), observó: «El Museo Antropológico hecho ha sido en España. Español es su fundador; español el arquitecto [...] españoles los artistas [...] españoles casi sus materiales todos; españoles los escultores [...], etc.» (p. 323). Continúa deplorando la dependencia española del conocimiento extranjero y termina así: «[Velasco] es el hombre científico que, hermanando el amor a la ciencia y la patria con el amor paternal, conduce a su casa y deposita bajo el techo del santuario médico los restos mortales de su adorada niña, cuyo embalsamado cadáver reposa ya en una capilla en el edificio, construida como parte integrante y recuerdo de origen del monumento que todo el mundo puede admirar en la calle de Granada [ahora Alfonso XII], en esta corte» (pp. 325-326).

65 Véase la obrita de González Velasco, P. (1878), A la humanidad, Madrid, Imprenta, Estereotipia y Galvanoplastia de Aribau y Compañía (Sucesores de Rivadeneyra), en la que hace varios comentarios sobre el programa humanitario ligado a su proyecto museístico; y también ROMERO DE TEJADA (1992), pp. 12, 15. Cabe destacar que la Escuela Libre de Medicina de Velasco, que ofrecía clases de anatomía a miembros de las clases sociales más inferiores, fue transferida a los sótanos del museo. Francos RodríGueZ, J. (s.f.), En tiempo de Alfonso XII (1875-1885), Madrid, Renacimiento, p. 11, escribe que «Velasco inició la urbanización del paseo de Atocha [el lugar del museo], pero además fue un grande amigo de los pobres y un fervoroso y práctico amante de la capital». 
Europa y las Américas durante el siglo XIX, apunta a un curioso paralelismo de relaciones. La antropología, en esta narrativa, nace de los huesos y tejidos de los muertos, de aquí lo grotesca y simbólicamente apropiado que resulta el cadáver momificado de Concha en el museo. Los difuntos vuelven a la vida en este estadio temprano de la historia de la antropología en España y, de modo semejante, suponen una vuelta a la percepción católica de lo real, tal y como se vio en los ejemplos de las voces de Chateaubriand, los cuerpos sacrificados de Pi y Molist y la amada hija del doctor Velasco. Además, el halo religioso que rodea a estas figuras de ausencia se fusiona íntimamente con lo que podemos llamar lo doméstico o lo familiar real. Es esta fusión, o confusión, esta transgresión o supresión de fronteras, la que produce en el siglo XIX incestuosas ficciones espectrales de lo siniestro, lo monstruoso y lo sagrado. La ciencia, por sí misma, no habría engendrado estos espectros, sino que fue más bien la confluencia histórica y cultural de ciencia y religión la que los hizo posibles. Los perfiles de la medicina y la antropología se hacen más pronunciados a medida que estas figuras de ausencia toman forma y la pérdida se transforma en fundamento sagrado de los sueños seculares.

Velasco no fue el primero, ni por supuesto el último, que intentara resucitar a un ser amado a través de la momificación. Tampoco fue el único en sacralizar y, por tanto, legitimar la ciencia al apelar al ámbito de lo espiritual a través de figuras de ausencia como la momificación o la autopsia. Por razones más amplias y también de comparación, vale la pena echar un vistazo a tres casos del siglo XX en que la mezcla de motivos personales y profesionales para revivir simbólica y emocionalmente a los muertos está imbuida de un halo sagrado. Cada uno de los tres casos promueve lo científico (o, en uno de los casos, lo pseudo-científico) apoyando y ampliando la autoridad y los poderes de explicación de la ciencia a través de medios no seculares.

En 1926 un inmigrante alemán llamado Karl Tanzler llegó a los Estados Unidos. Se autodenominaba Conde Carl von Cosel y trabajó como técnico de rayos $\mathrm{X}$ en un hospital de Key West (Florida). Allí conoció a una joven cubano-americana, Elena Milagro Hoyos, cuyos pulmones, enfermos de tuberculosis, le tocó radiografiar. Convencido de que una «divina odisea» lo había conducido hasta ella, el «conde» se enamoró perdidamente de ella, la agasajó con regalos y sufragó sus gastos médicos y, en última instancia, su funeral en octubre de 1931. Su obsesión por Elena lo llevó finalmente a robar su cuerpo, guardándolo en secreto en un avión sin alas que él mismo había construido, y trabajando día y noche para perfeccionar su cuerpo, es decir, embalsamarlo, de un modo tan «natural» que algún día llegara a levantarse y volviera a vivir. Von 
Cosel vivió y durmió con el cuerpo de Elena durante siete años, hasta que sus extraños modos de vida fueron descubiertos en 1940. Como ocurrió con el cuerpo de la hija del doctor Velasco, Elena ocupó el espacio sagrado de lo doméstico, el doble recreado de su cuerpo, al mismo tiempo familiar y extraño.

En la audiencia ante el juzgado, se le preguntó «¿Cree usted que hay aún vida en el cuerpo que pudiera ser resucitada?», a lo cual respondió: «Siempre queda vida en el cuerpo que pueda resucitarse con métodos especiales, como la incubación. No es el cuerpo físico. El cuerpo físico está dormido. Los ojos están en la oscuridad, pero los oídos todavía pueden escuchar» ${ }^{66}$. El conde también dejó unas memorias de sus experimentos con el cuerpo de Elena. «La momificación había comenzado en parte», escribió en algún momento. «Esto, sin embargo, no está más allá de la resurrección» ${ }^{67}$. La mañana del Domingo de Resurrección de 1933 se llega a identificar con la resurrección de ella. También afirma que hubo un momento en 1936 en que ella «despertó nuevamente a la vida $\rangle^{68}$. Para las autoridades de Florida, él parecía un hombre sano en casi todos los aspectos, pero era claramente un desequilibrado en lo que tocaba a Elena. Lo dejaron marchar, mientras insistían en enterrar de nuevo el cuerpo de Elena en un lugar secreto para que el conde no la volviera a desenterrar. Unas horas después de que dejara la ciudad, la cripta que él había construido para ella explotó. Durante las audiencias ante el tribunal, un enterrador local exhibía el cuerpo mientras casi 7.000 personas desfilaban ante él. En la década de los setenta, dos doctores que habían examinado el cuerpo de Elena en 1940 revelaron que la romántica necrofilia del conde había sido más que platónica.

¿Qué se puede inferir de todo esto? La creación de Von Cosel era un «cuerpo de retazos, reconstruido con cera y cosméticos», como se lee en un informe de este extraño episodio ${ }^{69}$. El conde lo expresaba así: «Reconstruí las partes perdidas, vendé aquellas que estaban rotas y las destruidas, que tuvieron que quedar fuera, las sustituí» ${ }^{70}$. En efecto, había elaborado una réplica a partir de los restos del cadáver, vendando los huesos, usando su cabello natural para hacer una peluca, aplicando cera y seda al rostro, e insertándole ojos de cristal. Su destartalada casa, que albergaba un avión que no podía volar y una suerte de laboratorio, era el escenario perfecto para esta «ciencia mística»

66 Harrison, B. (1997), Undying Love. The True Story of a Passion that Defied Death, Far Hills, New Jersey, New Horizon Press, p. 186.

67 HARRISON (1997), p. 136.

68 HARRISON (1997), p. 151.

69 HARRISON (1997), pp. 162-163.

70 HARRISON (1997), p. 191. 
que inevitablemente recuerda a escenas de la versión cinematográfica de Frankenstein de 1931 (el mismo año en que muriera Elena). Insinuando motivos humanitarios tras sus experimentos, el conde estaba convencido de que a miles de personas se les había practicado la autopsia y habían sido embalsamados de forma prematura, de que «la muerte no es siempre definitiva» ${ }^{71}$. Efectivamente, fue retratado como un científico mal comprendido, cuya investigación constituyó «una valiosa experimentación humana» ${ }^{72}$.

La descripción que da Von Cosel de su trabajo parece provenir tanto de un Wagner sentimental como de la tecnología corrupta. La reconstrucción que hizo del cuerpo de Elena convierte a esta en una especie de máquina. La opinión pública, sin embargo, optó en su mayoría por verlo a él como un romántico excéntrico. Pero esto ocurrió en 1940. Muerte y destrucción reinaban en Europa. Y él era alemán. En un artículo de periódico, el conde fue etiquetado como ese alemán «degenerado» $\mathrm{y}$, según se sabe, puesto bajo vigilancia del gobierno ${ }^{73}$.

¿Y qué ocurre con Elena? Procedente de una pobre familia de cigarreros cubanos, su marido la abandonó cuando le fue diagnosticada tuberculosis (la familia Hoyos al completo sucumbió a la misma enfermedad). Sin educación y ávida de cosas materiales, aceptó las atenciones y regalos de Von Cosel, pero tanto ella como su familia encontraron sus exigencias excesivas y consideraron injustificadas las reclamaciones que esgrimió para quedarse con ella. El conflicto estalló abiertamente. Nada de esto detendría más tarde a Von Cosel en el rapto del cuerpo y su posterior reconstrucción con el fin de satisfacer sus delirantes necesidades. La narrativa del conde y Elena es la del mito de Galatea-Pigmalión, pero imbuido de elementos de género, clase y etnia. Leída a través del prisma histórico y cultural de la época - guerra en Europa, vida inmigrante en Estados Unidos, la Depresión en las estancadas aguas de Key West, desiguales relaciones de género-, esta historia podría construirse como un mito de superioridad/inferioridad, con el «alemán» tecnológica y socialmente superior a cargo de la mujer «hispana». Pero también puede verse como una historia de resurrección en la que la medicina y la tecnología, por muy pobre y grotesco que fuera su uso en manos de Von Cosel, son revisadas (y mejoradas) en términos espirituales al sacralizar el cuerpo sin vida a través de su monstruoso doble.

71 HARRISON (1997), p. 122.

72 HARRISON (1997), p. 197.

73 HARRISON (1997), p. 221. 
Mi siguiente historia tiene lugar en Argentina y se centra en Eva Perón, la carismática líder populista no oficial y activista social del peronismo durante los años cuarenta y cincuenta. La odisea de su cadáver es un ejemplo de cómo la historia nacional (y de otro tipo) no solo puede simbolizarse sino también reencarnarse - de alguna manera, «revivir»- en un cuerpo sin vida. Si la resurrección del cuerpo de Elena Milagro Hoyos, aunque infundido de matices culturales e históricos, era un asunto personal, la vida que el cadáver de Evita asume parece personificar la historia de Argentina $^{74}$. Su cuerpo, asolado por el cáncer en la vida real, se revistió en la muerte de una doble cualidad, personal y patriótica, en la medida en que mujer y país se fusionaron en uno. «Ese cadáver [el de Evita] somos todos nosotros. Es el país» ${ }^{75}$.

El cuerpo de Evita fue embalsamado y expuesto al público de un modo bastante similar al de Lenin en la Rusia soviética. El doctor español que desempeñó esta labor, Pedro Ara, fue un distinguido anatomista totalmente volcado en su trabajo, que consistía en el cuidado regular del cadáver — que había sido colocado en una urna de cristal- desde 1952 a 1955, año en que un golpe militar derrocó al general Perón. Desde este momento, el cuerpo de Evita emprendió un complejo periplo: desaparece de las oficinas centrales del sindicato en Buenos Aires donde Ara había estado cuidando y perfeccionando el estado del cadáver; viaja de manera misteriosa hasta Italia, y es desenterrada y devuelta a Perón en 1971, a la sazón en el exilio y viviendo en Madrid con su tercera esposa. De aquí resultó un extraño ménage à deux et demie, como lo califica González-Crussi ${ }^{76}$, siendo el cuerpo finalmente devuelto a Buenos Aires, donde está ahora enterrado en el elegante Cementerio de La Recoleta. Durante dicho recorrido, también se hicieron réplicas de Evita en cera.

En una entrevista, el novelista Tomás Eloy Martínez, que recreó esta tortuosa odisea en Santa Evita (1995), recalcaba que «Evita fue el primero de los desaparecidos. Su familia nunca supo dónde estaba». «La historia de Argentina - dice él- está llena de cuerpos sin vida que fueron forzados a su pesar a moverse $\rangle^{77}$. Ciertamente su cuerpo suponía en 1955 una vergüenza y una amenaza al nuevo régimen militar que había depuesto a Perón.

74 Véase GonZÁLEZ-Crussi, F. (1994), The Day of the Dead and Other Mortal Reflections, Nueva York, Harcourt Brace and Co., pp. 18-31; y MARTínEZ, T.E. (1995), Santa Evita, Buenos Aires, Planeta.

75 MARTÍNEZ (1995), p. 387.

76 GONZÁLEZ-CRUSSI (1994), p. 30.

77 Streitfeld, D. (1996), Evita: The Body of a Novelist's Work. Washington Post, 24 de diciembre, C1-C2. 
Para el doctor Ara, salvar el cuerpo de Evita era una cuestión personal. Aunque no era peronista, estaba estrechamente ligado al régimen de Franco y admiraba de manera evidente a los Perón, especialmente a Evita. En El caso Eva Perón (1974), libro aparecido póstumamente, el doctor Ara describe en una prosa rebuscada y con perfecto protocolo burocrático los esfuerzos médicos y administrativos que emprendió para proteger el cadáver. Tomás Eloy Martínez sugiere que el arte del embalsamador es análogo al del biógrafo en el caso del doctor Ara: «los dos tratan de inmovilizar una vida o un cuerpo en la pose con que debe recordarlos la eternidad» ${ }^{78}$. La biografía de Ara es también, como continúa Martínez, un tipo de autobiografía de su arte funerario: «Ara reconstruye el cuerpo de Evita solo para poder narrar cómo lo ha hecho» (p. 157) ${ }^{79}$. Pero después de leer el libro de Ara, lo que yo encuentro es una rara escasez de detalles sobre el embalsamamiento, así como de otras medidas tomadas para momificar el cuerpo de Evita. Más bien, lo que predomina es una narrativa decididamente burocrática en la que el respeto y el acatamiento de los procedimientos burocráticos se confunden con el respeto por la disposición del cadáver de Evita. Como ocurría con el tratamiento que daba Von Cosel a su máquina mística (el cuerpo de Elena), el meticuloso cuidado que muestra Pedro Ara con los detalles técnicos y administrativos busca transmitir un sentido de lo sagrado no solo de la tarea y el deber a él asignados, sino también del cuerpo sin vida de Evita Perón.

La última narrativa es la historia de González-Crussi llamada «Moonlight Autopsy» y extraída de su libro The Day of the Dead (1994). GonzálezCrussi, profesor de patología (ahora emérito) en la sección de Pediatría del Memorial Hospital de Northwestern University y también escritor, permitió que un equipo de la BBC filmara una autopsia (así como otras escenas en que la muerte estaba presente de alguna manera), filmación de la cual surgió finalmente el libro arriba mencionado como una serie de meditaciones ensayísticas $^{80}$. Si bien ni el documental ni el libro están concebidos para impartir conocimientos de tipo técnico y biomédico, la atenta mirada de la cámara y la

78 Martínez (1995), p. 157; ARA, P. (1974), El caso Eva Perón (Apuntes para la historia), Madrid, CVS Ediciones.

79 MARTÍNEZ (1995), p. 157.

80 Consciente del posible desastre que supondría una autopsia televisada para sus relaciones públicas, González-Crussi medita sobre los motivos para filmarla. Al final, considera el documental «como un descarnado informe visual de la mortalidad»; GoNZÁLEZ-CRUSSI (1994), pp. 115-120, viii. 
preparación médica del patólogo dan forma de manera coherente a los contornos de esta necropsia.

Así, González-Crussi afirma haberse familiarizado, «como de costumbre, con los detalles del historial clínico del paciente fallecido. El sujeto es un niño de algo menos de 9 años de edad, que contrajo la enfermedad [sida] de su madre drogadicta». Sin embargo, González-Crussi abandona rápidamente esa postura distanciada tras leer el informe médico, «el cual desvela profundidades abismales del sufrimiento humano formuladas en la fraseología técnica e impersonal de los historiales clínicos, con una perenne inclinación por la forma pasiva en la construcción oracional» ${ }^{81}$.

Más reveladoras aún son sus observaciones en torno al cuerpo del niño: «Sobre la mesa, una presencia rubia, angelical, de cuyos párpados y mejillas ha huido el color, dejando tras de sí una palidez tal que no puede imaginarse nada peor. No hace mucho, esto era un niño; ahora es un cadáver, cubierto por el frío y la humedad propios de los cadáveres, y que aun así retiene algo de una presencia humana viviente. El tono lívido, el frío gélido y el perfil hundido no pueden deshacer el inefable residuo de humanidad que se aferra a lo que acaba de morir» ${ }^{82}$. No se trata de un simple «sujeto», sino de «una presencia rubia, angelical», un niño y no sencillamente un cadáver.

De modo similar, González-Crussi emplea la retórica literaria, una vez más, para describir la sala de autopsias inundada por una misteriosa luz lunar, una «sonata de claro de luna» de iluminación. Y esta «trémula luz extraña, espeluznante, perlada», con un imaginario que evoca a Chateaubriand y otros románticos, parece afectarle mentalmente, provocando en él «una pregunta insistente»: "¿Qué haces aquí? » ${ }^{83}$. Una suerte de estética clínica surge de esta elocuente meditación sobre los restos mortales, la cual lo conduce no solo a personalizar la muerte del niño, sino también a revivificar y, por tanto, conmemorar su corta presencia en este mundo.

Lo que González-Crussi ve encerrado en este pequeño cuerpo es «el ámbito de lo sagrado». «El abrir un cuerpo humano - comenta - equivale a penetrar en el mundo de lo sagrado» ${ }^{84}$. La autopsia viola ese espacio sagrado. Pero, aunque parezca mentira, con la presencia de la cámara y el equipo de rodaje, el patólogo empieza a ver cómo lo sagrado y lo profano ahora «se funden en uno

81 GONZÁlEZ-CRUSSI (1994), pp. 123-124.

82 GONZÁLEZ-CRUSSI (1994), p. 125.

83 GONZÁLEZ-CRUSSI (1994), pp. 128-129.

84 GoNZÁLEZ-CRUSSI (1994), pp. 129-130. 
con el impulso de un maremoto» ${ }^{85}$. Otros observadores - el equipo de rodajele hacen percibir la escena de manera diferente. En este sentido, sus percepciones recién descubiertas - e, indirectamente, las del equipo- han creado una nueva realidad, la comprensión de cómo lo real (el cuerpo material) funciona como la entrada a algo no real, a lo sagrado o lo siniestro.

El niño de la historia de González-Crussi está muerto y vivo a la vez. Vivo gracias a las palabras y observaciones del patólogo. Vivo metafórica y afectivamente porque las palabras lo conmemoran, conservándolo del mismo modo en que el embalsamador - el doctor Velasco, Von Cosel, Pedro Ara- momifica las reliquias mortales de cuerpos que una vez estuvieron vivos. ¿Hasta qué punto la creencia religiosa ha jugado un papel en imaginar el cuerpo sin vida como algo ausente y vivo en estas narrativas del siglo XX? La presencia de una cultura hispánica (cubana y española) en Key West y en la familia de Elena Milagro Hoyos influyó probablemente en la presentación que Carl Von Cosel hizo de su adorado cuerpo (y en algunas de las respuestas públicas al episodio). Un cuadro de su ángel de la guarda, Santa Cecilia, colgaba de la pared del dormitorio de Elena. Y su sepulcro final mostraba una réplica de su cuerpo en escayola y cera, junto con una máscara mortuoria en yeso de París, algunas fotografías, el rosario de Elena y un crucifijo ${ }^{86}$. Un periodista habló de un «marcado componente español» en la reacción pública al suceso, añadiendo: «fue en España [...] donde el cuerpo momificado del inigualable guerrero El Cid fue sacado de su tumba, sentado en un caballo gigante y enviado a encabezar las renqueantes fuerzas españolas contra los moros, quienes quedaron confundidos por la aparición del campeón regresado de la muerte para conquistarlos de nuevo» ${ }^{87}$. Pero ante todo la insistencia del mismo Von Cosel en querer resucitar a Elena señala un impulso espiritual innegable; la muerte, decía, «no es siempre definitiva».

El catolicismo se mezcla, histórica y culturalmente, con la percepción popular de Evita Perón como mártir y santa, imaginario que también se ajusta a la virginal Concha, la divina novia Elena e incluso el niño angelical arrasado por el sida. El cuerpo de Evita fue dispuesto con un rosario entre sus manos, una insignia del partido peronista sobre su pecho y con la bandera argentina cubriendo su cuerpo. Finalmente, el doctor español que conservó sus restos la miraba de acuerdo con una perspectiva católica, lo cual no resulta sorprendente dados los usos a que estaba sujeto el catolicismo bajo el régimen de

85 GONZÁlEZ-CRUSSI (1994), p. 132.

86 HARRISON (1997), p. 265.

87 Cit. en HARRISON (1997), pp. 199-200. 
Franco en la doctrina del «Nacionalcatolicismo». La sinceridad religiosa del doctor Ara asume tintes burocráticos en sus recuerdos, que sirven, si no al estado peronista, ciertamente a la noción misma de estado, ya que las preocupaciones humanitarias se vuelven patrióticas. Este giro nacionalizador de un gesto humanitario - la protección del cuerpo enormemente simbólico de Eva Perón- era ya visible en la narrativa de una medicina y ciencia en estado de avance, tal como la contaban Velasco y Pi y Molist.

No se explicita una creencia religiosa ortodoxa en el ensayo de GonzálezCrussi, pero un halo espiritual recubre sus revelaciones de un ámbito sagrado dentro del cuerpo ${ }^{88}$. De manera un tanto sobria, el autor aprecia que es «imposible resucitar a una persona muerta»; solo se puede «reactivar» lo que no es irreversible 89 . En todo caso, argüiría yo, el patólogo resucita de hecho el cuerpo de este niño en otros niveles, al imaginarlo como una especie de reliquia - un dominio sagrado - y viendo de este modo el cuerpo sin vida no solo como una fuente de poder, sino también como un vínculo entre los vivos y los muertos, un rasgo que aparece asimismo en otras narrativas aquí expuestas. Paradójicamente, por medio de las técnicas y observaciones propias de la autopsia, el autor ha conseguido reanimar el cuerpo, recordándonos una vez más la misteriosa naturaleza de los muertos, una naturaleza en que deseo y terror son parte de la misma experiencia. También nos recuerda que a veces las distinciones entre lo siniestro freudiano y lo espiritual resultan borrosas ante la realidad compleja del cuerpo sin vida.

$Y$ es que es el terror lo que también nos llena con el poder del cuerpo de este niño. Lo que se revivifica en este relato no es simplemente el recuerdo y la presencia de su cuerpo, sino la consciencia de lo que este alberga. Lo que mató al niño aún posee una suerte de vida o, quizás de modo más preciso, habita en un estado de limbo en algún lugar intermedio; el agente de contagio

$8^{80}$ En su autobiografía, GONZÁLEZ-CruSSI (1998), There is a World Elsewhere, Nueva York, Riverhead Books, pp. 128, 134, apunta que él no había sido «educado en el catolicismo practicante» de su México natal. Sin embargo, afirma también, «nuestra propia tradición judeo-cristiana contenía muchos elementos que exaltaban la valía y dignidad del cuerpo. Que el Hijo de Dios eligiera ser hombre en la Encarnación acaba de una vez y completamente con cualquier idea de que haya algo esencialmente maligno o degradante en tener un cuerpo perecedero». Este último comentario aparece mientras describe su reacción al degradante modo en que dos cadáveres fueron traídos a rastras a una clase de anatomía para que se les practicara una autopsia, clase que entonces se llevaba a cabo en un edificio colonial de la vieja facultad de medicina de la UNAM. Esta estructura, irónicamente, había sido en algún momento sede de la Inquisición.

89 GONZÁLEZ-CRUSSI (1994), pp. 137-138. 
está todavía en su cuerpo, mucho más que en las narrativas anteriores, en las que la fiebre tifoidea, la tuberculosis y el cáncer producen sus propias angustias particulares. El equipo de rodaje toma las precauciones necesarias, poniéndose la indumentaria de protección adecuada; $\mathrm{y}$, periódicamente, uno de los cámaras pregunta: «¿Estoy bien aquí?» o «¿Es segura esta distancia?» ${ }^{90}$.

El poder del cuerpo infectado de sida resuena en estas tímidas frases. Aun después de muerto, este cuerpo específico está aún vivo; algo persiste en el ocaso del virus, hundido en la profundidad del cuerpo. Por tanto, de un modo muy real y terrible, este cuerpo está verdaderamente muerto y vivo al mismo tiempo. Parece el doble encarnado del «Cuarto Cuerpo» de Valéry, real e imaginario a partes iguales, moldeado por el cada vez más débil rastro de un halo espiritual, viviendo en una artificial luz lunar. Al mismo tiempo, la autopsia también dice mucho del poder y el fracaso de la ciencia en sí, a pesar de los adelantos humanitarios y concomitante profesionalización que fueron de tanta importancia a médicos como Pi y Molist, Velasco y Ara. GonzálezCrussi generaliza el impacto de la experiencia - el cuerpo infectado de si$\mathrm{da}$ - sugiriendo que la muerte en sí es el último agente de contagio ${ }^{91}$. En un lugar anterior de su libro, afirma que «la tendencia a evitar nombrar esta realidad [de la muerte] debe de ser universal» ${ }^{92}$. Universal, sí, pero las formas de evadirla y los modos de utilizarla no son universales. Están profundamente imbricados en una cultura y una historia, ya sea ese contexto la medicina y la ciencia españolas del siglo XIX, el Key West de los años treinta, la Argentina peronista o la cultura algo más particular surgida de la epidemia del sida. Al final, quizás lo que González-Crussi califica de evasión sea otra forma de llamar la atención sobre la naturaleza espectral e incomprensible de la muerte, sobre la pérdida, que todas estas narrativas humanitarias intentan superar por medio de resurrecciones simbólicas, de la creación de dobles literales o figurados en los que lo único que vive es la muerte misma.

(Trad. de Daniel García-Donoso)

Recibido: 9 de junio de 2010.

Aceptado: 10 de enero de 2011.

\footnotetext{
90 GONZÁlEZ-CRUSSI (1994), p. 133.

91 GONZÁLEZ-CRUSSI (1994), p. 134.

92 GONZÁlEZ-CRUSSI (1994), p. 5.
} 